\section{Best Historical Materials 2013}

\section{RUSA CODES History Section Historical Materials Committee}

RUSA History Section Materials Committee contributing members: Jennifer Hootman, Jerilyn Marshall, Sara E. Morris, Jacob Sherman, Matthew J. Wayman, Agnes Haigh Widder, Mary Wilke, and Nicholas Wyant, editor and chair.
Each year, the RUSA/CODES History Section Historical Materials Committee selects an assortment of resources that reflect the best resources for historical research. The 2013 list follows. All resources received a final review on November 1, 2013.-Editor

War of 1812 in the Collections of the Lilly Library http://collections.libraries.iub.edu/warof1812

The War of 1812 is often a forgotten war in American history. Resources, let alone digital objects, are often hard to access. Indiana University has made available content such as correspondence, maps, and government reports in its digital collection War of 1812 in the Collections of the Lily Library. This site is easy to use and gives great contextual background on each topic area. The topics include the lead up to the war, the war itself, and its ramifications. Each topic has five digital objects that relate to the content. Each object has zoom features and can be downloaded as a PDF. The only drawback is that there is no transcript for the correspondence. Another outstanding feature is an interactive timeline that chronologically arranges topics and subject tags that are easily searched. The ideal users would be high school and college students who need primary sources on the War of 1812 and the early republic.—Jacob Sherman

\section{Baltimore 68: Riots and Rebirth. Special Collections University of Baltimore} http://archives.ubalt.edu/bsr

Baltimore entered a two-week period of civil unrest after the April 1968 assassination of Martin Luther King. Although sparked by King's death, Baltimore's riots were part of the Civil Rights Movement. Baltimore's African Americans lived in inadequate housing, faced high rates of unemployment, and suffered from the general decline associated with white flight-all of these factors contributed to riots. During the unrest the governor called in the National Guard, the president sent members of the army, six people died, and significant damage occurred to the city. As part of a fortieth anniversary of the riots, the University of Baltimore hosted an academic conference. Baltimore 68, the online component of this commemoration, is an impressive public-history site that explains what happened and how it continues to affect the city. The site makes many primary sources accessible, including over sixty oral histories, digitized newspaper clippings, local government documents, news footage, and numerous photo galleries. These and other primary sources make it possible to understand what happen and for a student to write a paper or complete a project. However, there are other features that make Baltimore 68 
far more than a static digital collection. There is a downloadable "Driving Tour" that describes where key events occurred and how they still influence the current cityscape. The "1968 Retrospective Calendar" demarks significant events occurring both nationally and locally with hyperlinked articles to primary sources. This feature puts events of 1968 into context with one another. Baltimore 68 does an excellent job at documenting this turbulent time and provides guidance to other institutions embarking in commemorating an event electronically. -Sara E. Morris, University of Kansas, Lawrence, Kansas

\section{Civil War Diaries and Letters. University of Iowa Libraries} http://digital.lib.uiowa.edu/cwd

The University of Iowa's Civil War Diaries and Letters website contains digitized items from the university's Special Collections. There are two primary navigational features: "Browse the Collection," which has a dropdown box that allows the selection of diaries, correspondence, photographs, or items from a single year, and a standard search box in the upper-right corner. Both options lead to a standard search results page, in which "Civil War Diaries and Letters" is selected on the left. Using the "browse" feature simply conducts a search for that type of document. The results page allows the user to further narrow the search via the search text box at the top and expandable categories on the lower left. Each result is displayed with a thumbnail image along with title and year directly below. Hovering over a thumbnail produces a pop-up window that displays that item's topical subjects, date of original, and any available description. Clicking on an item leads to the digitized document along with detailed description immediately below. Thumbnails for individual pages are on the right, along with a "Content" tab that displays an expandable table of contents for the document. A "Text" tab generates a searchable transcription of the document in standard type. The site is attractive and easy to navigate, with minimal clutter on the homepage. There is however no "About" page containing descriptive information about the collection, nor any link to information regarding the scope and overall contents, though one may find by browsing "All" that there are 228 documents. Civil War Diaries and Letters is a useful and attractive resource for Civil War and Iowa history enthusiasts.-Matthew J. Wayman, Penn State Schuylkill, Schuylkill Haven, Pennsylvania

Hurricane Digital Memory Bank. Roy Rosenzweig Center for History and New Media, George Mason University and the University of New Orleans

www.hurricanearchive.org

The Hurricane Digital Memory Bank (HDMB), organized in November 2005 by George Mason University's Roy Rosenzweig Center for History and New Media (CHNM) and the University of New Orleans (UNO), is an impressive effort in collecting and preserving first-hand accounts of Hurricanes Katrina and Rita and their aftermath for historical record. Because the CHNM and UNO partnered with the Smithsonian Institution's National Museum of American History and several other national and Gulf Coast area organizations and individuals to quickly launch the HDMB website, primary resources were captured as they were being created. The bank consists of digital objects including contributed images, podcasts, videos, and blog postings of personal accounts from anyone affected by these hurricanes. Users can browse by image, personal stories, oral histories, maps, or tags or search through several metadata fields and collections. Contributed collections also can be browsed, which include the Smithsonian National Museum of American History Hurricane Katrina Photos, United States Coast Guard Released Photographs of Hurricanes Katrina and Rita, Katrina's Kids Project Artwork, Hellicane: Poets Respond to Hurricane Katrina, The Center for Oral History and Cultural Heritage at The University of Southern Mississippi, and several more. Given the Award of Merit for Leadership in History, and being the largest free public archive of Katrina and Rita, the Hurricane Digital Memory Bank makes a unique and powerful contribution to research in multiple disciplines and to the preservation of an American experience for future generations.-Jennifer Hootman, Minitex, University of Minnesota-Twin Cities, Minneapolis

\section{KnowLA: Encyclopedia of Louisiana. Louisiana Endow- ment for the Humanities}

www.knowla.org

With the cute play on words the name KnowLA says it all. Presently intended for interested lifelong learning adults, this website brings together a wide range of information about Louisiana history and culture. Future stated plans include making the site more child-friendly, which will increase the benefit to school age children. At present, the categories covered by the site include architecture, art, folklife, history, literature, and music. The category government/politics only appears when one clicks on the categories tab. It is not included on the dropdown menu of categories. Knowing that Louisiana has a rich history related to government and politics, one can hope that this category is added to the dropdown menu, as people will miss it unless they go to the page for categories. What is especially interesting is the sites' incorporation of images, audio files, videos, multimedia, along with documents. Thus if one searches for Marsalis in the upper right hand corner search box (instead of using the navigation bar) one finds three entries for Branford, Ellis, and Wynton Marsalis along with links to images and a video. The site is also searchable by region which allows one to easily key in on such regional wonders as the Troyville Earthworks in Northeastern Louisiana. It has a created date of 2010-13 and content is actively being added to the site. This website is recommended for anyone who wants to know more about Louisiana.-Mary Wilke, Center for Research Libraries

RICHES of Central Florida: Regional Initiative for Collecting the History, Experiences and Stories of Central Florida. University of Central Florida

http://riches.cah.ucf.edu

RICHES of Central Florida incorporates several 


\section{FROM COMMITTEES OF RUSA}

interdisciplinary public history projects focused on Central Florida and its residents. It currently includes seven projects on such diverse topics as local businesses, GLBT history, home movies, local travel, documentaries, Florida surfing, and military veterans. Some of these projects, such as the GLBT History Museum of Central Florida and the "Surfing Florida" exhibit, also have their own websites that are supplemented by digitized documents and other artifacts from RICHES. Development of the RICHES project began in 2009, with Phase 1 completed in 2011. The RICHES Mosaic Interface (RMI) is the main gateway for the digital projects and includes images, documents, podcasts, oral histories, and films. The interface includes mapping of search results to connect each document with a location in Central Florida. Search results can be enlarged, and each item includes a full description. Overall, this site is visually attractive and informative, with the ability to connect local historical events spatially and temporally. The search engine is easy to use but may take some exploration to understand all of its features. -Jerilyn Marshall, University of Northern Iowa

\section{Digital Collections for the Classroom: Shakespeare's} The Tempest and Utopias of the European Renaissance. Hana Layson and Kasey Evans

http://dcc.newberry.org/collections/shakespeare-tempestutopias-european-renaissance

This is a teaching tool website for use in high school or college classrooms. It is quite short, containing pages from several texts and images from different Renaissance period books, along with questions students are to answer about the content, so they will learn how Renaissance writers and artists wanted people to imagine the New World and about the concept of utopia. Hana Layson is coordinator of digital collections for classroom use at the Newberry Library. Kasey Evans is an associate professor of English literature at Northwestern University. The site was produced in conjunction with Evans' Teachers as Scholars seminar lecture at the Newberry Library, Chicago, May 20, 2011, called "Utopias of the European Renaissance." The site presents short interpretive narratives about the topic as it relates to each of several books followed in each case first by a digital image from it and then several questions to the students which could be used for oral classroom discussion or as homework assignments. These are the works the site presents: Sir Thomas More's Utopia, 1516; André Thevet's New Found Worlde or Antarctike, 1557; Michel de Montaigne's essay "Of Cannibals," 1603 in English; Thomas Hariot's Briefe and True Report of the New Found Land of Virginia, 1590; engravings by Theodor de Bry; Theodor de
Bry's Grandes Voyages, v. 4 America, 1594; and Henry Fuseli's painting of Act 1 Scene 2 of Shakespeare's The Tempest, 1803 edition, published by John Boydell. The first three works are represented by narrative texts with accompanying questions; the others are represented by illustrations with accompanying questions. This is a successful, basic teaching tool, which accomplishes its purpose straight forwardly, without glitz. High school libraries would not be likely to have these works, even in modern editions, so bringing them to the classroom via digital projection for discussion is admirable. Some college and university libraries might have copies of these books in their libraries' rare book rooms, but they would not circulate. In any case, projecting the images for the whole class to see and discuss together is worthwhile use of digital technology in education.-Agnes Haigh Widder, Michigan State University, East Lansing, Michigan

\section{Papers of the War Department: 1784 to 1800. Roy Rosenzweig Center for History and New Media, George Mason University \\ http://wardepartmentpapers.org}

Papers of the War Department is a historical resource of tremendous value. This archive seeks to reconstruct the lost records of the War Department that resulted from a fire in 1800. A novel aspect of the archive is the crowd-sourcing digitization that the project uses to fulfill the creation of records. Users (1,538 as of October) are able to register with the site and then transcribe records from uploaded scans of documents. As these records were all handwritten, the work of transcription can be challenging. However, the finished product is immensely valuable to historians studying the early years of US history. Researchers are able to look for specific mentions in a basic search or can simply browse what has already been digitized. The search option allows the researcher to formulate precise queries, undoubtedly the kind of tool most needed by scholars within such specialized archives. Browsing documents is accomplished two different ways: chronological order or by author. Document information includes helpful metadata such as the format of the document, author and recipient name, as well as related people or groups. All of this information is linked to other documents in the collection, which makes the discovery of connects between places and people all the easier. Any researcher that has stared at seemingly meaningless scribbles on a page will appreciate the work done at the Roy Rosenzweig Center for History and New Media at George Mason University. -Nicholas Wyant, Indiana University, Bloomington 